\title{
ON WEAKLY NONLINEAR BOUNDARY VALUE PROBLEMS ON INFINITE INTERVALS
}

\author{
BENJAMIN FREEDMAN AND JESÚs RODRÍGUEZ
}

\begin{abstract}
In this paper, we study weakly nonlinear boundary value problems on infinite intervals. For such problems, we provide criteria for the existence of solutions as well as a qualitative description of the behavior of solutions depending on a parameter. We investigate the relationship between solutions to these weakly nonlinear problems and the solutions to a set of corresponding linear problems.
\end{abstract}

Mathematics subject classification (2010): 34A34, 34B15, 34B40, $47 \mathrm{~J} 07$.

Keywords and phrases: Boundary value problems, infinite intervals, ordinary differential equations, implicit function theorem.

\section{REFERENCES}

[1] R. Agarwal, D. O'Regan, Discrete Systems on Infinite Intervals, Computers \& Mathematics with Applications 35, 9 (1998), 97-105.

[2] R. Agarwal, D. O'Regan, Infinite Interval Problems Modeling the Flow of a Gas Through a SemiInfinite Porous Medium, Studies in Applied Mathematics 108, 3 (2002), 245-257.

[3] R. Agarwal, D. O'Regan, Non-linear boundary value problems on the semi-infinite interval: an upper and lower solution approach, Differential Equations and Dynamical Systems 49, 1-2 (2002), $129-140$.

[4] R. Agarwal, D. O'Regan, Singular problems on the infinite interval modelling phenomena in draining flows, IMA Journal of Applied Mathematics 66, 6 (2001), 621-635.

[5] R. Agarwal, D. O'Regan, Infinite Interval Problems for Differential, Difference and Integral Equations, Springer, 2001.

[6] R. Agarwal, D. O'REgAn, B. YAn, Unbounded solutions for singular boundary value problems on the semi-infinite interval: Upper and lower solutions and multiplicity, Journal of Computational and Applied Mathematics 197, 2 (2006), 365-386.

[7] S. Chow, J. K. Hale, Methods of Bifurcation Theory, Spring, Berlin, 1982.

[8] L. CESARI, Functional analysis and periodic solutions of nonlinear differential equations, Contributions to differential equations, 1, (1963), 149-187.

[9] L. CESARI, Functional analysis and Galerkin's method, The Michigan Mathematical Journal, 11, 4 (1964), 385-414.

[10] G. DAI, R. MA, Global bifurcation and nodal solutions for a Sturm-Liouville problem with a nonsmooth nonlinearity, Journal of Difference Equations and Applications, 265, 8 (2013), 1443-1459.

[11] D.L. ETheridge, J. Rodríguez, Scalar discrete nonlinear two-point boundary value problems, Journal of Difference Equations and Applications, 4, 2 (1998), 127-144.

[12] J. Henderson, H. WAng, Positive Solutions for Nonlinear Eigenvalue Problems, Journal of Mathematical Analysis and Applications, 208, (1997), 252-259.

[13] J. R. L. WebB, G. Infante, Positive solutions of nonlocal boundary value problems involving integral conditions, NoDEA, 15, (2008), 45-67.

[14] J. R. L. Webb, G. Infante, Positive Solution of Nonlocal Boundary Value Problems: A Unified Approach, Journal of the London Mathematical Society, 74, 3 (2006), 673-693. 
[15] J. R. L. WEBB, G. Infante, Multiple positive solutions of resonant and non-resonant nonlocal boundary value problems, Nonlinear Analysis: Theory, Methods, and Applications, 71, 3-4 (2009), 1369-1378.

[16] A. Karts atos, Advanced Ordinary Differential Equations, Mariner Pub. Co., 1980.

[17] A. Kartsatos, A boundary value problem on an infinite interval, Proceedings of the Edinburgh Mathematical Society, 19, 3 (1975), 245-252.

[18] S. LAng, Real and Functional Analysis, vol. 142 of Graduate Texts in Mathematics, Springer-Verlag, New York, 1993.

[19] B. Freedman, J. Rodríguez, On the Solvability of Nonlinear Differential Equations Subject to Generalized Boundary Conditions, Differential Equations and Applications, 10, 3 (2018), 317-327.

[20] B. Freedman, J. Rodríguez, On Nonlinear Boundary Value Problems in the Discrete Setting, Journal of Difference Equations and Applications, 25, 7 (2019), 994-1006.

[21] R.B. Guenther, J.W. LeE, D. O’Regan, Boundary Value Problems on Infinite Intervals and Semiconductor Devices, Journal of Mathematical Analysis and Applications, 116, 7 (1986), 335-348.

[22] J. HALE, Ordinary differential equations, Pure and applied mathematics, Vol. XXI, WileyInterscience, 1969.

[23] R. MA, Existence of Positive Solutions for Second-Order Boundary Value Problems on Infinity Intervals, Applied Mathematics Letters 16, (2003), 33-39.

[24] R. MA, Nonlinear discrete Sturm-Liouville problems at resonance, Nonlinear Analysis 67, (2007), 3050-3057.

[25] D. Maroncelli, J. RodríGUEZ, Existence theory for nonlinear Sturm-Liouville problems with nonlocal boundary conditions, Differential Equations and Applications 10, 2 (2018), 147-161.

[26] D. Maroncelli, J. Rodríguez, Periodic behaviour of nonlinear, second-order discrete dynamical systems, Journal of Difference Equations and Applications 22, 2 (2016), 280-294.

[27] J. RodRIGUEZ, Nonlinear discrete systems with global boundary conditions, Journal of Mathematical Analysis and Applications, 286, 2 (2003), 782-794.

[28] J. RodrígueZ, Z. Abernathy, On the Solvability of Nonlinear Sturm-Liouville Problems, Journal of Mathematical Analysis and Applications, 387, 1 (2012), 310-319.

[29] J. RodrígueZ, Z. Abernathy, Nonlinear discrete Sturm-Liouville problems with global boundary conditions, Journal of Difference Equations and Applications, 18, 3 (2012), 431-445.

[30] J. RodrígueZ, A.J. SuAREZ, On nonlinear perturbations of Sturm-Liouville problems in discrete and continuous settings, Differential Equations and Applications 8, 3 (2016), 319-334.

[31] J. RoDRÍGUEZ, D. SWEET, Discrete boundary value problems on infinite intervals, Journal of Difference Equations and Applications, 7, 3 (2001), 435-443.

[32] J. Rodríguez, D. SweEt, Nonlinear Boundary Value Problems on Sequence Spaces, Journal of Difference Equations and Applications 8, 2 (2002), 153-162.

[33] J. RodrígueZ, P. TAYLOR, Scalar discrete nonlinear multipoint boundary value problems, Journal of Mathematical Analysis and Applications 330, 2 (2007), 876-890.

[34] J. F. RodríguEZ, Existence theory for nonlinear eigenvalue problems, Appl. Anal., 87 (2008) 293301.

[35] N. Rouche, J. Mawhin, Ordinary differential equations: Stability and periodic solutions, Pittman Advanced Pub. Program, 1980.

[36] M. URABE, Galerkin's procedure for nonlinear periodic systems, Archive for Rational Mechanics and Analysis, 20, (1965) 120-152. 